\title{
Cyclic Voltammetry and Computational Chemistry Studies on the Evaluation of the Redox Behavior of Parabens and other Analogues
}

\author{
Eric de S. Gil, *,a Carolina H. Andrade, ${ }^{a}$ Núsia L. Barbosa, ${ }^{a}$ Rodolpho C. Braga ${ }^{a}$ and \\ Sílvia H. P. Serrano ${ }^{b}$
}

\author{
${ }^{a}$ Faculdade de Farmácia, Universidade Federal de Goiás, $1^{a}$ Av. c/ Praça Universitária, \\ 74605-220 Goiânia-GO, Brazil \\ 'Instituto de Química, Universidade de São Paulo, Av. Prof. Lineu Prestes, 748, \\ Cidade Universitária, 05508-000 São Paulo-SP, Brazil
}

\begin{abstract}
Os parabenos são conservantes antimicrobianos amplamente utilizados na indústria farmacêutica, cosmética e alimentícia. A cadeia alquila ligada ao grupo éster define algumas características físico-químicas destes compostos, incluindo coeficiente de partição e propriedades redox. A voltametria e estudos computacionais foram realizados a fim de avaliar o comportamento redox desses compostos fenólicos e de outros análogos. Uma forte correlação entre os potenciais redox e os efeitos indutivos dos substituintes químicos dos parabenos foi observada. Usando voltametria cíclica e eletrodo de trabalho de carbono vítreo, foi observado um único pico de natureza irreversível, em torno de $0,8 \mathrm{~V}$ para metilparabeno (MP), etilparabeno (EP), propilparabeno (PP), butilparabeno (BP), benzilparabeno (BzP) e análogos fenólicos p-substituídos. O efeito indutivo eletrodoador de grupos alquila foi demonstrado pela mudança do potencial de oxidação para valores menos positivos conforme o aumento do número de carbonos e, portanto, o processo de oxidação dos parabenos (e outros análogos fenólicos) às formas quinonoídicas mostrou forte dependência do padrão de substituição.
\end{abstract}

Parabens are antimicrobial preservatives widely used in pharmaceutical, cosmetic and food industries. The alkyl chain connected to the ester group defines some important physicochemical characteristics of these compounds, including the partition coefficient and redox properties. The voltammetric and computational analyses were carried out in order to evaluate the redox behavior of these compounds and other phenolic analogues. A strong correlation between chemical substituents inductive effects of parabens with redox potentials was observed. Using cyclic voltammetry and glassy carbon working electrode, only one irreversible anodic peak was observed around $0.8 \mathrm{~V}$ for methylparaben (MP), ethylparaben (EP), propylparaben (PP), butylparaben (BP), benzylparaben $(\mathrm{BzP})$ and $p$-substituted phenolic analogues. The electrodonating inductive effect of alkyl groups was demonstrated by the anodic oxidation potential shift to lower values as the carbon number increases and, therefore the parabens (and other phenolic analogues) oxidation processes to the quinonoidic forms showed great dependence on the substituent pattern.

Keywords: preservatives, electroanalysis, computational chemistry, substituent pattern, phenolic compounds

\section{Introduction}

Parabens are compounds commonly used as antimicrobials preservatives in foodstuffs, cosmetics, pharmaceutical and personal care. ${ }^{1,2}$ They are esters of $p$-hydroxybenzoic acid, with low molecular weight, relatively high lipophilicity, and are easily absorbed through the skin. ${ }^{3}$

*e-mail: ericsgil@gmail.com
Their biological properties as antibacterial and antifungal activity ${ }^{4}$ increase synergistically if associations are employed. Thus, while the antimicrobial activity increases as function of the chain length of the ester group, the water solubility decreases. As consequence, the most common preservative system contains $0.3 \% \mathrm{MP}$ (methylparaben) and $0.1 \%$ PP (propylparaben). ${ }^{5}$

The use of these preservatives have become very popular due to their low toxicity, effective activity and 
broad spectra, as well as worldwide regulatory acceptance and low cost. ${ }^{5,6}$ Parabens are completely absorbed through the skin and from gastrointestinal tract, being completely metabolized and rapidly excreted in the urine. ${ }^{7,8}$ The metabolism involves hydrolysis to $p$-hydroxybenzoic acid with further conjugation and, none of these compounds or their metabolites are accumulated in the body. ${ }^{5}$ Another interesting property is their antioxidant activity, which arouses great interest due to parabens' importance in biological and industrial processes. ${ }^{9}$

The alkyl chain of the ester group defines the lipophilicity of alkyl parabens, which is responsible for the first step of antimicrobial activity, the cell membrane penetration. ${ }^{9}$ Furthermore, the donor character of alkyl chain have shown some influence on the phenol oxidation to correspondent quinone. ${ }^{10,11}$

In the light of the great importance of these preservatives, the quantitative analysis and the investigation of their physicochemical properties are very useful.

Most of the analytical methods reported in the literature are based on high performance liquid chromatography (HPLC) and other chromatographic techniques, which are very appropriate for quantitative purposes and could also provide some valuable information about the hydro/ lipophilicity. ${ }^{12,13}$ However, these techniques are expensive and time consuming, and cannot provide information regarding the antioxidant properties.

In spite of the high sensitivity and selectivity of electroanalytical methods, few studies have been conducted on the application of voltammetry to establish correlations between the electrochemical behavior and the chemical structural pattern. ${ }^{9,14,15}$

Therefore, the present study aims to investigate the electrochemical behavior of alkyl parabens and other phenolic analogues such as cresol, $p$-nitrophenol and $p$-chlorophenol and compute relevant electronic properties through quantum-chemical calculations, in order to evaluate the eventual correlations. The results will help to better understand the redox behavior of paraben compounds.

\section{Experimental}

\section{Chemicals and solutions}

All phenolic compounds: methylparaben (MP), ethylparaben (EP), propylparaben (PP), butylparaben (BP), benzylparaben (BzP), $p$-chlorophenol, $p$-nitrophenol, $p$-cresol and $p$-hydroxybenzoic acid (HBzA) were purchased from SIGMA S.A. Phosphate buffer, ethanol, sodium sulfate, sodium nitrate, sodium phosphate, sodium chloride, potassium chloride, lithium chloride, ammonium chloride were purchased from Merck S.A, Vetec Ltda and Impex Ltda and were of analytical grade. All solutions were prepared by direct dissolution of the salts on purified water from Milli-Q plus system (Millipore). Stock solutions of phenolic compounds in the concentration of $10^{-2} \mathrm{~mol} \mathrm{~L}^{-1}$ were prepared using 1:1 (v/v) water:ethanol.

\section{Apparatus}

The electrochemical analyses were performed using a potentiostat/galvanostat $\mu$ AUTOLAB TYPE III from Eco Chemie BV coupled to GPES software for acquisition and treatment of voltammetric data. Glassy carbon electrode $\left(\varnothing 2 \mathrm{~mm}^{2}\right), \mathrm{Hg} / \mathrm{Hg}_{2} \mathrm{Cl}_{2}, \mathrm{KCl}_{\text {(sat) }}$ and platinum wire were used as working, reference and auxiliary electrodes, respectively.

All $\mathrm{pH}$ measurements were made using a combined glass electrode (type BlueLine; Shott) coupled to a digital pHmeter (Labmeter) model PHS-3B.

\section{Procedures}

Voltammetric measurements were carried out as follows. A $10 \mathrm{~mL}$ aliquot of phosphate buffer $\left(0.1 \mathrm{~mol} \mathrm{~L}^{-1}\right)$ was placed in the voltammetric cell and, the required aliquot of sample solution, was added into the voltammetric cell in order to get a phenolic concentration of $0.25 \mathrm{mmol} \mathrm{L}^{-1}$. The solution was stirred during $2 \mathrm{~min}$ and the voltammogram recorded in the range of -0.25 to $1.25 \mathrm{~V}$ (or 1.25 to $-0.25 \mathrm{~V}$ ) using variable scan rate in the range of 10 to $100 \mathrm{mV} \mathrm{s}^{-1}$.

The $\mathrm{pH}$ influence on the electrochemical behavior was evaluated adjusting the $\mathrm{pH}$ solution in the range of $3.0 \leq \mathrm{pH} \leq 8.0$ with $\mathrm{NaOH}$ or $\mathrm{HCl} 0.1 \mathrm{~mol} \mathrm{~L}^{-1}$. The ionic strength influence was evaluated in the range of 0.01 to $0.5 \mathrm{~mol} \mathrm{~L}^{-1}$ by varying the buffer solution concentrations. Moreover, the influence of the supporting electrolyte on the anodic peak potentials was also evaluated by changing the phosphate buffer electrolyte solution for other salt solutions using different anions $\left(\mathrm{PO}_{4}^{3-}, \mathrm{CH}_{3} \mathrm{COO}^{-}, \mathrm{SO}_{4}^{-}, \mathrm{Cl}^{-}\right.$and $\left.\mathrm{NO}_{3}^{-}\right)$and different cations $\left(\mathrm{K}^{+}, \mathrm{Li}^{+}, \mathrm{Na}^{+}\right.$and $\left.\mathrm{NH}_{4}^{+}\right)$.

\section{Computational studies}

The redox reactivity of phenolic compounds $(\mathrm{ArOH})$, such as paraben, follows at least two mechanisms, which may occur in parallel: ${ }^{16,17}$ a one-step hydrogen atom transfer (HAT, equation 1) and/or a single-electron transfer and proton transfer (SET-PT, equation 2):

$$
\begin{aligned}
& \mathrm{ArOH}+\mathrm{R}^{\bullet} \rightarrow \mathrm{ArO}^{\bullet}+\mathrm{RH} \\
& \mathrm{R}^{\bullet}+\mathrm{ArOH} \rightarrow \mathrm{R}^{-}+\mathrm{ArOH}^{+} \rightarrow \mathrm{ArO}^{\bullet}+\mathrm{RH}
\end{aligned}
$$


The reactivity of $\mathrm{ArOH}$ can be estimated for the first case by $\mathrm{O}-\mathrm{H}$ bond dissociation enthalpy (BDE), or by adiabatic ionization potential (IP) value and reactivity of the $\mathrm{ArOH}^{\circ+}$ cation, for the second mechanism. ${ }^{16,17}$ In equation 1, the reactivity of $\mathrm{ArOH}$ can be estimated by the calculated $\mathrm{O}-\mathrm{H}$ bond dissociation enthalpy (BDE) value, whereas in equation 2, by the calculated adiabatic ionization potential (IP) value and by the reactivity of the $\mathrm{ArOH}^{++}$cation. ${ }^{16,17}$ The BDE and IP are important molecular descriptors for studying the redox behavior of phenolic compounds since that low values for these parameters are related with ease of $\mathrm{O}-\mathrm{H}$ bond breaking and ease of electron transfer process, respectively, which makes the electron abstraction easier. ${ }^{18}$

The oxidation behavior of the paraben compounds has been investigated by means of post-Hartree-Fock approach (second order Møller-Plesset perturbation theory, MP2). All calculations were carried out using the ORCA program package ${ }^{19,20}$ in our local cluster (36 Intel ${ }^{\circledR}$ Xeon ${ }^{\circledR}$ Processors). Geometry optimizations were done using the recently developed second-order Möller-Plesset perturbation (RIJCOSX-MP2) method ${ }^{21}$ in combination with a triple- $\zeta$ quality plus polarization functions TZVP basis set. ${ }^{22}$ The density fitting and chain of spheres (RIJCOSX) approximations ${ }^{23}$ were used to accelerate the calculations in combination with the auxiliary basis sets TZVP/J and TZVP/C used from TurboMole library ${ }^{24}$ developed by the Karlsruhe group.

Single-point calculations employing the orbitaloptimized second-order Möller-Plesset perturbation theory (OO-MP2 $)^{25}$ were performed using the extensively polarized basis sets of triple- $\zeta$ quality including high angular momentum polarization functions (def2-TZVPP). ${ }^{26}$ The RIJCOSX ${ }^{23}$ in combination with the def2-TZVPP/J and def2-TZVPP/C auxiliary basis sets, ${ }^{26}$ was used to accelerate the calculations. Frequency calculations were done at the same level of theory for both ArOH neutral molecule and $\mathrm{ArO}^{*}$ and $\mathrm{ArOH}^{+\bullet}$ species. These values were used to characterize the stationary points on the potential surface and obtain the zero point energies (ZPE) at a $298.15 \mathrm{~K}$ and 1 atm using unscaled vibrations. ZPE values were included in all BDE and IP relative energies.

In this investigation, the more relevant electronic properties for phenolic compounds, such as $\mathrm{O}-\mathrm{H}$ bond dissociation enthalpy (BDE), HOMO (highest occupied molecular orbital) and LUMO (lowest unoccupied molecular orbital) energies of neutral, radical and radicalcation species, energy gap ( $\left.\mathrm{DE}=\mathrm{E}_{\mathrm{LUMO}}-\mathrm{E}_{\text {номо }}\right)$ and ionization potential (IP), have been studied. The $\mathrm{O}-\mathrm{H}$ BDEs in gas phase were obtained at $298.15 \mathrm{~K}$ using the sum of electronic and thermal enthalpies. The BDEs were calculated as follows: $\mathrm{BDE}=\mathrm{Hr}+\mathrm{Hh}-\mathrm{Hn}$ in which $\mathrm{Hr}$ is the enthalpy of radical generated through $\mathrm{H}$-atom abstraction, $\mathrm{Hh}$ is the enthalpy of hydrogen atom [ -0.49765 hartree] and $\mathrm{Hn}$ is the enthalpy of neutral molecule. ${ }^{27}$ The adiabatic ionization potential (IP) was calculated from the Koopmans' theorem (orbital energy consideration represented by subscript $\mathrm{O}$ ): $\mathrm{IP}_{\mathrm{O}}=-\mathrm{E}_{\text {номо }}$ and from the total energies denoted with subscript $E$ : $\mathrm{IP}_{\mathrm{E}}=\mathrm{E}_{\text {cation }}-\mathrm{E}_{\text {neutral }}$, where $\mathrm{E}_{\text {cation }}$ is the energy of the molecule derived from electron-transfer (radical cation) and $\mathrm{E}_{\text {neutral }}$ is associated to the neutral molecule. ${ }^{28}$

\section{Results and Discussion}

The alkyl paraben compounds: MP, EP, PP and BP, as well as the arylparaben, $\mathrm{BzP}$ are oxidized to the corresponding quinonoidic forms as represented in Figure 1.<smiles></smiles>

Figure 1. Proposed electrochemical oxidation mechanism for paraben compounds.

Using cyclic voltammetry and glassy carbon electrodes, only one irreversible anodic peak was observed around $0.8 \mathrm{~V}$ for all parabens, Figure 2.

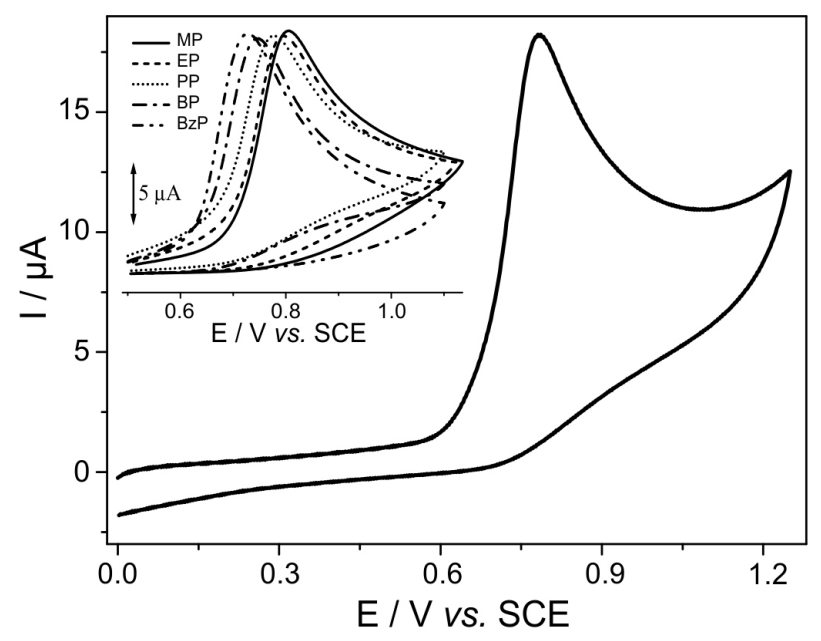

Figure 2. Cyclic voltammograms obtained at glassy carbon electrode in $0.1 \mathrm{~mol} \mathrm{~L}^{-1}$ phosphate buffer, pH 7.0, containing $0.25 \mathrm{mmol} \mathrm{L}^{-1} \mathrm{MP}$ solution. Experimental conditions: scan range from $-0.25 \mathrm{~V}$ to $1.25 \mathrm{~V}$, scan rate of $100 \mathrm{mV} \mathrm{s}^{-1}$. Inset: voltammograms obtained for MP, EP, PP, BP and $\mathrm{BzP}$, from $0.5 \mathrm{~V}$ to $1.1 \mathrm{~V}$ and the same other experimental conditions.

It can be also observed that the anodic peak potentials shift to less positive values with the increase of the chain length in the R substituent. Such effect may be attributed to the electron donating character of the alkyl chain, 
which may balance the electron withdrawn effect of ester group. This may facilitate the phenolic moiety oxidation, being that the longer the alkyl chain length, the stronger this effect will be.

By plotting the anodic peak potential vs. molecular weight, a linear relationship was obtained, Figures 2 and 3.

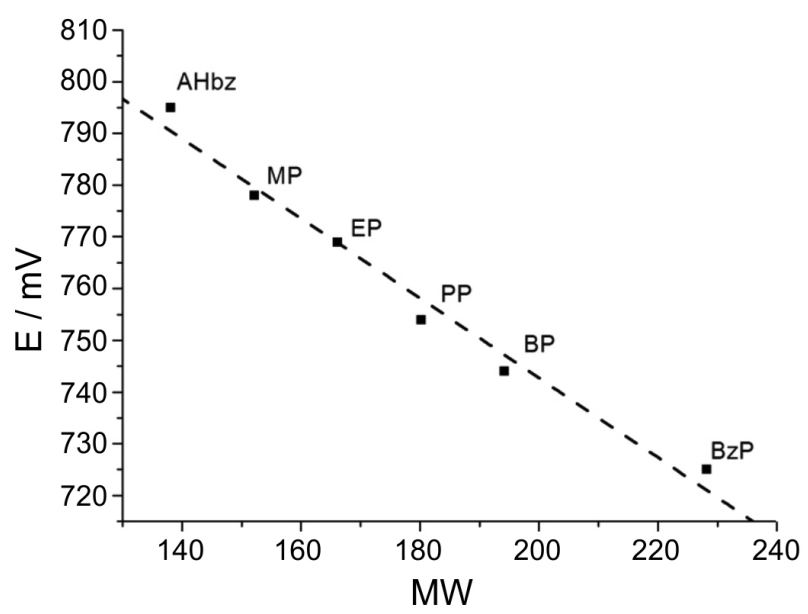

Figure 3. $\mathrm{E}_{\mathrm{p}, \mathrm{a}}$ vs. MW plots for paraben compounds $(\mathrm{r}=0.9895)$. Experimental conditions as described on Figure 2.

In phenolic compounds, the behavior of the $\mathrm{OH}$ groups is mostly influenced by the neighboring groups as well as by the geometry of the molecule. Figure 3 reinforces the hypotheses that the withdrawn effect of ester group is diminished, as the alkyl chain increases. As a result, the electron density on the aromatic ring is enhanced, which may contribute to the electron loss. It is noteworthy that in the case of paraben series, the chain length also determines the steric conformations, which exert important influence over the electron density of hydroxyl group. In order to confirm these assumptions we conducted some computational chemistry studies.

In this study, RIJCOSX-MP2 level of theory, with a triple- $\zeta$ quality plus polarization functions, TZVP basis set, were used. Despite all recent progress, it would be useful to have a wave-function-based ab initio method, with the same QCISD (Quadratic Configuration Interaction with Single and Double Excitation) or CCSD (Coupled-Cluster Singles and Doubles) reliably of results at a low cost. In this context, the results of MP2 for open-shell molecules can be improved both in accuracy and stability, if the orbitals are optimized alongside the double excitation amplitudes..$^{29,30}$ The orbital-optimized MP2 method (OO-MP2) was chosen for single point calculations for it improves the results for open-shell molecules, reactions barriers and radicals, and it reduces the spin contamination in electronically difficult situations (unrestricted Hartree-Fock) with OO-MP2 over MP2 substantial benefits. ${ }^{29}$
The reactivity of phenolic compounds $(\mathrm{ArOH})$ can be estimated by calculating the $\mathrm{O}-\mathrm{H}$ bond dissociation enthalpy (BDE) which the smaller value should improve the biological activity. The parabens calculated BDEs values, and the enthalpies of the neutral and radical species are presented in Table 1.

In the hydrogen atom transfer (HAT) mechanism, a spontaneous $\mathrm{H}$ atom is abstracted from the phenolic hydroxyl group and transported to the free radical. In this mechanism, the breaking of $\mathrm{O}-\mathrm{H}$ bond is, in nature, homolytic. The BDE physicochemical parameter governs this mechanism since a weaker $\mathrm{O}-\mathrm{H}$ bond implies in a greater reaction velocity, which contributes to the oxidation process. As seen in Table 1, the lowest value for BDE gas-phase was of $92.807 \mathrm{kcal} \mathrm{mol}^{-1}$ for BzP, and $95.763 \mathrm{kcal} \mathrm{mol}^{-1}$ for BP. The results indicated that the alkyl chain side affects the BDE values, and therefore, a greater amount of energy is required to break the $\mathrm{OH}$ bonds on MP and $\mathrm{EP}$.

Table 1. Entalpy and bond dissociation enthalpy (BDE) computed in the gas phase for the paraben compounds at OO-MP2/def2-TZVPP level of theory

\section{HAT Mechanism}

\begin{tabular}{llll} 
Paraben & $\mathrm{Hn} / \mathrm{Ha}^{\mathrm{a}}$ & $\mathrm{Hr} / \mathrm{Ha}^{\mathrm{b}}$ & $\mathrm{BDE} /\left(\mathrm{kcal} \mathrm{mol}^{-1}\right)^{\mathrm{c}}$ \\
\hline $\mathrm{MP}$ & -534.460 & -533.800 & 102.032 \\
$\mathrm{EP}$ & -573.673 & -573.019 & 98.428 \\
$\mathrm{PP}$ & -612.881 & -612.229 & 96.858 \\
$\mathrm{BP}$ & -652.103 & -651.453 & 95.763 \\
$\mathrm{BzP}$ & -764.578 & -763.932 & 92.807 \\
\hline
\end{tabular}

${ }^{\mathrm{a}} \mathrm{Hn}=$ enthalpy of neutral molecule, in hartree; ${ }^{\mathrm{b}} \mathrm{Hr}=$ enthalpy of radical generated through $\mathrm{H}$-atom abstraction, in hartree; ${ }^{\mathrm{B} D E}$ s computed with zero point energy (ZPE).

The calculated electronic properties for paraben compounds such as HOMO and LUMO energies, energy gap $\left(\mathrm{DE}=\mathrm{E}_{\mathrm{LUMO}}-\mathrm{E}_{\text {номо }}\right)$ and ionization potential (IP) are listed in Table 2, which also shows the experimental oxidation potential $\left(\mathrm{E}^{\circ}\right)$ for the paraben molecules.

Electron donation of the selected compounds was also studied. Adiabatic IPs were calculated in the gas phase for the most stable structure of neutral form of the compounds as the difference between the electronic energy of the corresponding ionized form (radical cation) and that of the neutral species corrected with ZPE. According to one electron transfer (SET-PT) mechanism, the removal of an electron from the HOMO of the neutral compound generates radical cation species. 
Table 2. Molecular descriptors calculated from the total energies and the orbital energies obtained at OO-MP2/def2-TZVPP level of theory and the experimentally obtained oxidation potentials $\left(\mathrm{E}^{\circ}\right.$ ) for the paraben molecules

\begin{tabular}{|c|c|c|c|c|c|c|}
\hline \multirow[b]{2}{*}{ Paraben } & \multicolumn{5}{|c|}{ Molecular descriptors ${ }^{\mathrm{a}}$ and oxidation potentials } & \multirow[b]{2}{*}{$\mathrm{E}^{\circ} / \mathrm{V}^{\mathrm{c}}$} \\
\hline & $\mathrm{E}_{\text {Номо }}$ & $\mathrm{E}_{\text {LUMO }}$ & $\Delta \mathrm{E}^{\mathrm{b}}$ & $\mathrm{IP}_{\mathrm{E}}$ & $\mathrm{IP}_{\mathrm{O}}$ & \\
\hline MP & -9.007 & 2.558 & 11.565 & 8.936 & 9.007 & 0.778 \\
\hline $\mathrm{EP}$ & -9.006 & 2.557 & 11.563 & 8.754 & 9.006 & 0.769 \\
\hline $\mathrm{PP}$ & -8.995 & 2.568 & 11.562 & 8.579 & 8.995 & 0.754 \\
\hline $\mathrm{BP}$ & -8.989 & 2.562 & 11.551 & 8.261 & 8.989 & 0.744 \\
\hline $\mathrm{BzP}$ & -8.969 & 2.478 & 11.447 & 7.473 & 8.969 & 0.725 \\
\hline
\end{tabular}

The IP properties that are displayed in Table 2 were both obtained from the total energies denoted with subscript $\mathrm{E}$ and from the orbital energies through Koopman's theorem. The orbital energies are represented by the subscript $\mathrm{O}$. The IP properties from the total energies are based on the difference of total electronic energies, when an electron is removed with reference to the neutral compound and are called energy-vertical $\left(\mathrm{E}_{\mathrm{E}}\right)$. The IP properties from the orbital energies are based on the difference between the HOMO and LUMO energies of the neutral compound and are known as orbital-vertical $\left(\mathrm{E}_{\mathrm{O}}\right)$. The lowest gas-phase IP value from energy-vertical is $7.473 \mathrm{eV}$ for $\mathrm{BzP}$, followed by $8.261 \mathrm{eV}$ for BP suggesting that the BzP and BP may be more efficient electron donors than MP, EP and PP.

Moreover, a correlation between oxidation electrode potentials and ionization potentials has been found. Several of these correlations have been previously reported for other systems..$^{31,32}$ The correlation graph between calculated ionization potentials (IP) and oxidation potentials ( $\mathrm{E}^{\circ}$ ') is shown in Figure 4. A good linear relationship is observed between the IP and $\mathrm{E}^{\circ}\left(\mathrm{R}^{2}=0.95\right)$. IP and $\mathrm{E}^{\circ}$ ' decrease with the increasing of the alkyl chain length of the paraben compounds. The lowest values of IP and $\mathrm{E}^{\circ}$, were found for $\mathrm{BzP}$ and $\mathrm{BP}$, meaning that these compounds are easier oxidized than PP, EP and MP, showing that the electron donating character of the alkyl side chain contributes slightly to the oxidation process. These results are in accordance to the electrochemical data.

It is noteworthy that the IP for BzP from the orbitalvertical method $\left(E_{0}\right)$ is higher than the energy-vertical method $\left(\mathrm{E}_{\mathrm{E}}\right)$ by $1.89 \mathrm{eV}$ (Table 2). The same is observed with the other compounds, but to a lesser extent. In previous investigations, it has been found that for most of the commonly used exchange-correlation functional such as B3LYP, B3PW91, Koopman's theorem is not satisfied

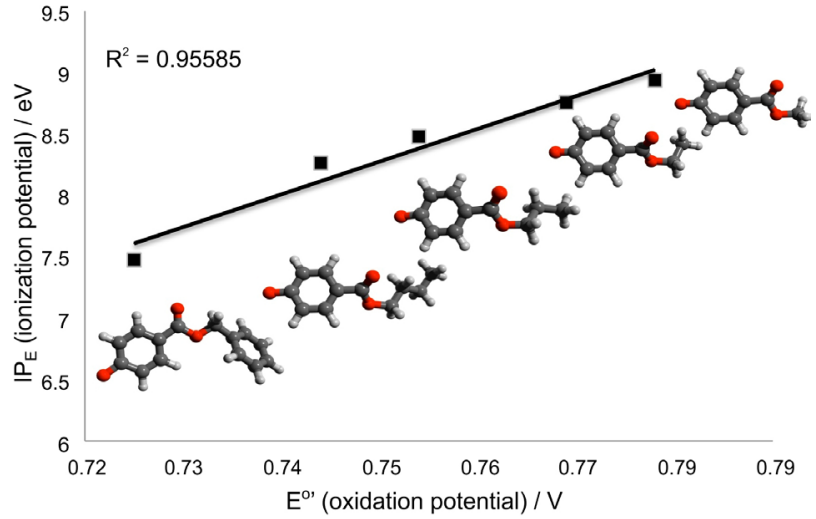

Figure 4. Correlation graph between the experimental oxidation potentials $\left(\mathrm{E}^{\circ}\right)$ and the ionization potential $\left(\mathrm{IP}_{\mathrm{E}}\right)$ for the paraben compounds, calculated at the OO-MP2/def2-TZVPP level of theory.

accurately ${ }^{33}$ Koopman's theorem is valid only when there is no difference between the orbital of neutral and ionized compounds, which in turn is not possible. The molecular orbital theory provides just an approximation that is not quantitatively reliable, since Koopman's theorem does not consider the effects of electron correlation and orbital relaxation.

The energy of the lowest unoccupied molecular orbital $\left(\mathrm{E}_{\mathrm{LUMO}}\right)$ and the energy of the highest occupied molecular orbital $\left(\mathrm{E}_{\text {номо }}\right)$ can be used as measurement of the molecular ability to accept or donate an electron, respectively. The molecular electron donating ability has been also characterized by the HOMO energy values: the higher the HOMO energy, the easier the oxidation process. The computed HOMO energy values of paraben compounds are $-9.007 \mathrm{eV}$ for MP, $-9.006 \mathrm{eV}$ for EP, $-8.995 \mathrm{eV}$ for PP, $-8.989 \mathrm{eV}$ for $\mathrm{BP}$ and $-8.969 \mathrm{eV}$ for BzP. Benzylparaben which records a higher HOMO energy value, exhibits a facilitated oxidation process.

The energy gap is the necessary energy to promote an electron from the highest occupied molecular orbital to the lowest unoccupied molecular orbital. This molecular descriptor gives a crude estimate of the relative ability a molecule has to act as a reducing or oxidizing agent. The higher the reactivity the inferior is the energy gap between the HOMO and LUMO. Although quite subtle, there is a small difference in the energy gap between the paraben compounds (Table 2). The energy gap is smaller for parabens with larger side chains, such as propyl and butyl. Moreover, BzP shows a smaller gap, demonstrating its easy oxidation process. Therefore, the correlation between the reactivity of the paraben compounds and their chain length was achieved, since the greater the length the smaller the energy gap.

The electrostatic potential maps (EPM) of the methyl, butyl and benzyl paraben molecules in their neutral and 
radical forms are shown in Figure 5. The analysis of these maps have indicated that electronic density of the phenolic hydroxyl group increases with the increasing of the alkyl chain length of the paraben compounds in their neutral forms (Figure 5, top), which facilitates the oxidation process. Moreover, the EPM also indicated that the electrons in the oxidized paraben forms are delocalized (Figure 5, bottom) and a significant negative potential is on the electronegative oxygen atoms in the paraben molecules.
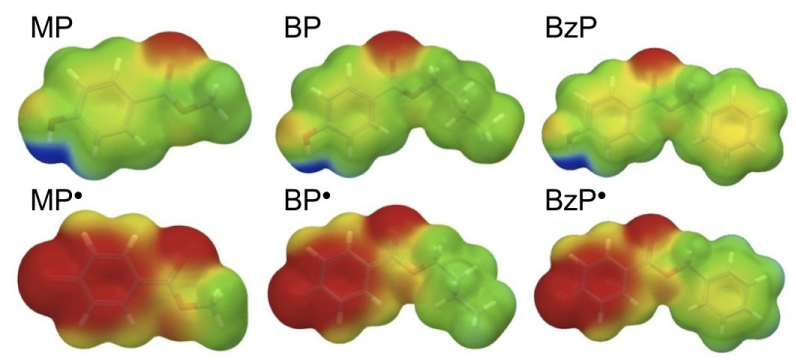

Figure 5. Electrostatic potential maps for MP, $\mathrm{BP}$ and $\mathrm{BzP}$ in their neutral (top) and radical (bottom) forms. The color code is in the range of -55.0 (deepest red) to +100.0 (deepest blue) $\mathrm{kcal} \mathrm{mol}^{-1}$ (see online).

The results obtained using the computational chemistry approach are in accordance with the electrochemical data, demonstrating a stabilization of paraben radical by the side chain of the ester group. Thus, the oxidation of the parabens herein studied has shown to be dependent on the substitution pattern of the side chain of the ester moiety.

Figure 6 presents the cyclic voltammograms obtained for $p$-nitrophenol, $p$-chlorophenol and $p$-cresol solutions in the same conditions as those used for MP. The remarkable differences between electron donor/withdrawn character of these different substituents resulted in higher potential shifts than those observed for different parabens. For instance, the $\mathrm{E}_{\mathrm{p}, \mathrm{a}}$ value of $p$-cresol was $300 \mathrm{mV}$ lower than that one observed for MP, showing clearly that higher electron donor character makes easier the oxidation process. Moreover, the $p$-nitrophenol has exhibited the highest value of anodic potential peak. It is easily explained by its great withdrawing character (negative inductive effect, $\mathrm{I}^{-}$, and resonance withdrawing effect, $\mathrm{R}^{-}$), which makes electron loss during the oxidation process more difficult.

Furthermore, the $p$-chlorophenol has presented the anodic peak inside the range of parabens group, fact which was attributed to the opposite effects of the chloro substituent, as electron donation by resonance $\left(\mathrm{R}^{+}\right)$ dominates the inductive effect $\left(\mathrm{I}^{-}\right)$(Figure 7). Herewith, the electron withdrawing effect over the oxidized hydroxyl group decreases in the following order: nitro > methyl-ester (MP) $>$ chloro $>$ methyl, and can be explained by means of inductive and resonance effects (Figure 7).

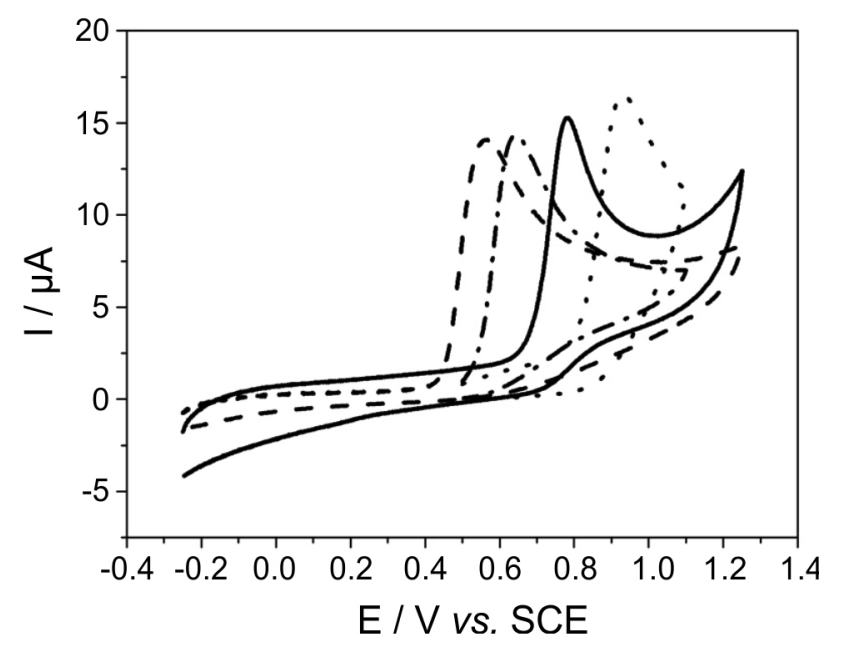

Figure 6. Cyclic voltammograms obtained at glassy carbon electrode in phosphate buffer $0.1 \mathrm{~mol} \mathrm{~L}^{-1}(\mathrm{pH} 7.0)$ containing $0.25 \mathrm{mmol} \mathrm{L}^{-1} \mathrm{MP}(-)$, $p$-cresol (-- -), p-nitrophenol (...) and $p$-chlorophenol (-.-.). Scan range from $-0.25 \mathrm{~V}$ to $1.25 \mathrm{~V} ; \mathrm{n}=100 \mathrm{mVs}^{-1}$.

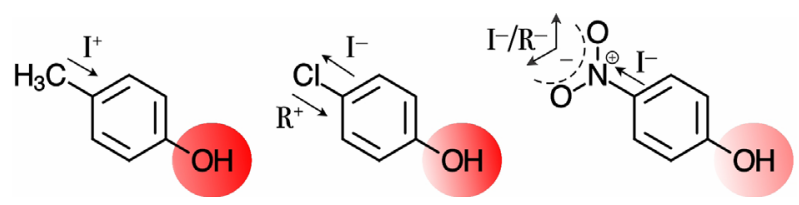

Figure 7. Electronic effects of different phenolic substituents. Positive inductive effect $\left(\mathrm{I}^{+}\right)$, negative inductive effect $\left(\mathrm{I}^{-}\right)$, electron donation by resonance $\left(\mathrm{R}^{+}\right)$and electron withdrawing by resonance $\left(\mathrm{R}^{-}\right)$.

The cyclic voltammograms obtained with glassy carbon electrode for $0.25 \mathrm{mmol} \mathrm{L}^{-1} \mathrm{MP}$ in different electrolytes show one $\mathrm{pH}$ dependent oxidation peak. Moreover, it was observed that the oxidation of phenol group is facilitated at low proton concentration, Figure 8.

Additionally, for $\mathrm{pH}$ values higher than 7.0 the parabens suffer alkaline hydrolysis giving 4-hydroxybenzoic acid. Probably the calculated $\mathrm{pK}$ values represent the $\mathrm{pK}$ of the 4-hydroxybenzoic acid and their derivatives and therefore will be very similar. Besides, the linear equation of the $\mathrm{E}_{\mathrm{p}, \mathrm{a}}$ versus $\mathrm{pH}$ curve $(57.6 \mathrm{mV} / \mathrm{pH})$, shows clearly that the same number of electron and proton are involved in the electrochemical electrode process as expected for the oxidation of phenol group. ${ }^{34}$

Finally, the influence of supporting electrolyte on the anodic peak potentials was also evaluated. The voltammetric behavior of MP was anion dependent while the cation influence was negligible, Figure 9.

The small potential was obtained for experiments carried on sodium phosphate, while the highest potential for sodium nitrate. The decreasing order of the anodic peak potentials, $\mathrm{PO}_{4}{ }^{3-}<\mathrm{CH}_{3} \mathrm{COO}^{-}<\mathrm{SO}_{4}{ }^{2-}<\mathrm{Cl}^{-} \leq \mathrm{NO}_{3}{ }^{-}$, suggests stronger interaction of some oxygenated anions with ester groups or, eventually, stabilization of phenoxyl radical, intermediate reactive specie during the oxidation 

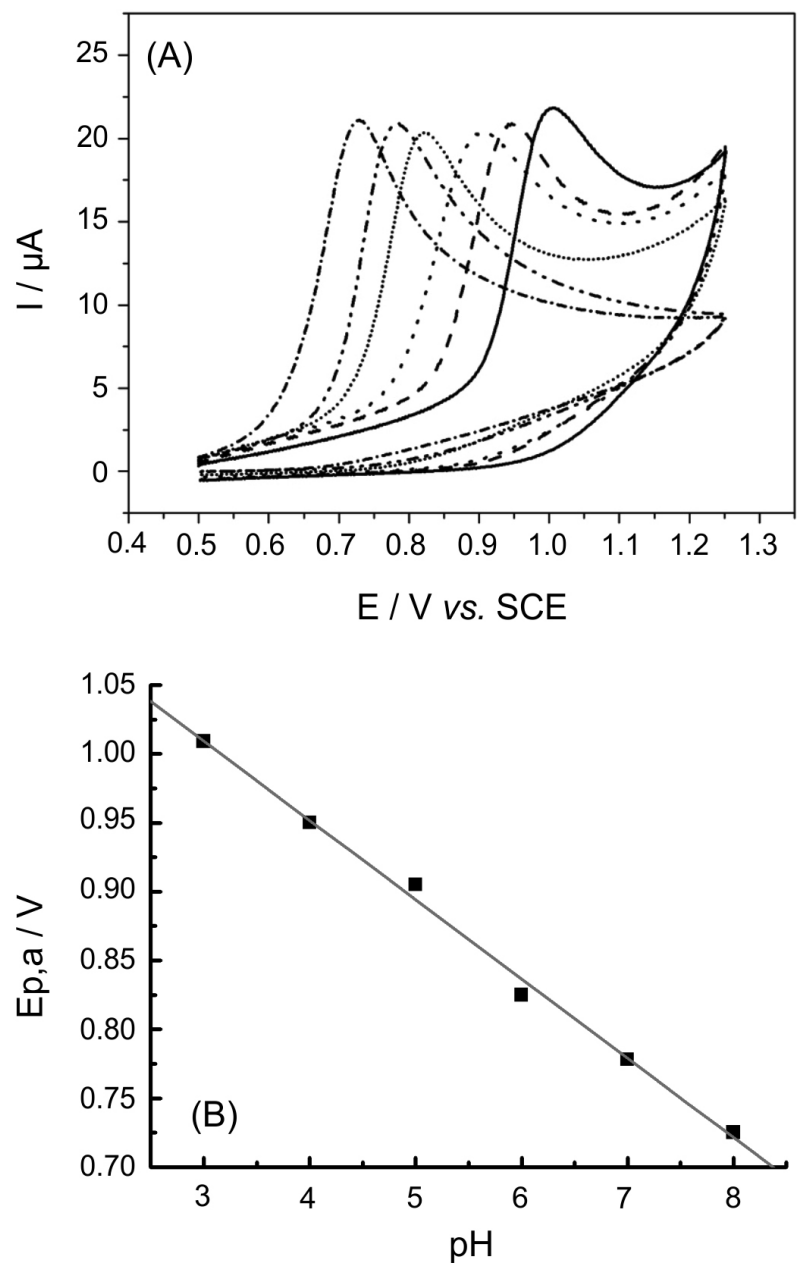

Figure 8. (A) Cyclic voltammograms obtained for $0.25 \mathrm{mmol} \mathrm{L}^{-1}$ of MP at glassy carbon electrode in different $\mathrm{pH}$ solutions: $8.0(-.-\cdot), 7.0(-. \cdot-)$, $6.0(\ldots), 5.0(--), 4.0(--)$ and $3.0(-)$. Scan range from -0.25 to $1.25 \mathrm{~V}$; scan rate of $100 \mathrm{Vs}^{-1}$. (B) $\mathrm{E}_{\mathrm{p}, \mathrm{a}} \mathrm{vs} \mathrm{pH}$ curve obtained for MP. Linear equation: $\mathrm{E}_{\mathrm{p}, \mathrm{a}}(\mathrm{V})=1.18(\mathrm{~V})-0.0576 \mathrm{pH}$. Other conditions such as Figure 8(A).

of phenol to the respective quinonoidic form. Moreover, the peak current levels can be correlated to the mobility of the different cations in the solution, being more intense for $\mathrm{K}^{+}$. Indeed, both the ions mobility of and the ionic strength exert positive effect on current signal.

\section{Conclusions}

Using cyclic voltammetry and glassy carbon electrodes, only one irreversible anodic peak was observed around $0.8 \mathrm{~V}$ for all parabens. Increasing the alkyl chain length, the overall electron donating character of alkyl side chain slightly contributed to the oxidation process due to the increasing of electron density over the aromatic ring, which facilitated the phenolic group oxidation. This positive inductive effect of alkyl groups was evidenced by the potential shift to lower potentials as the carbon number increases. At the same time, the oxidation potentials are
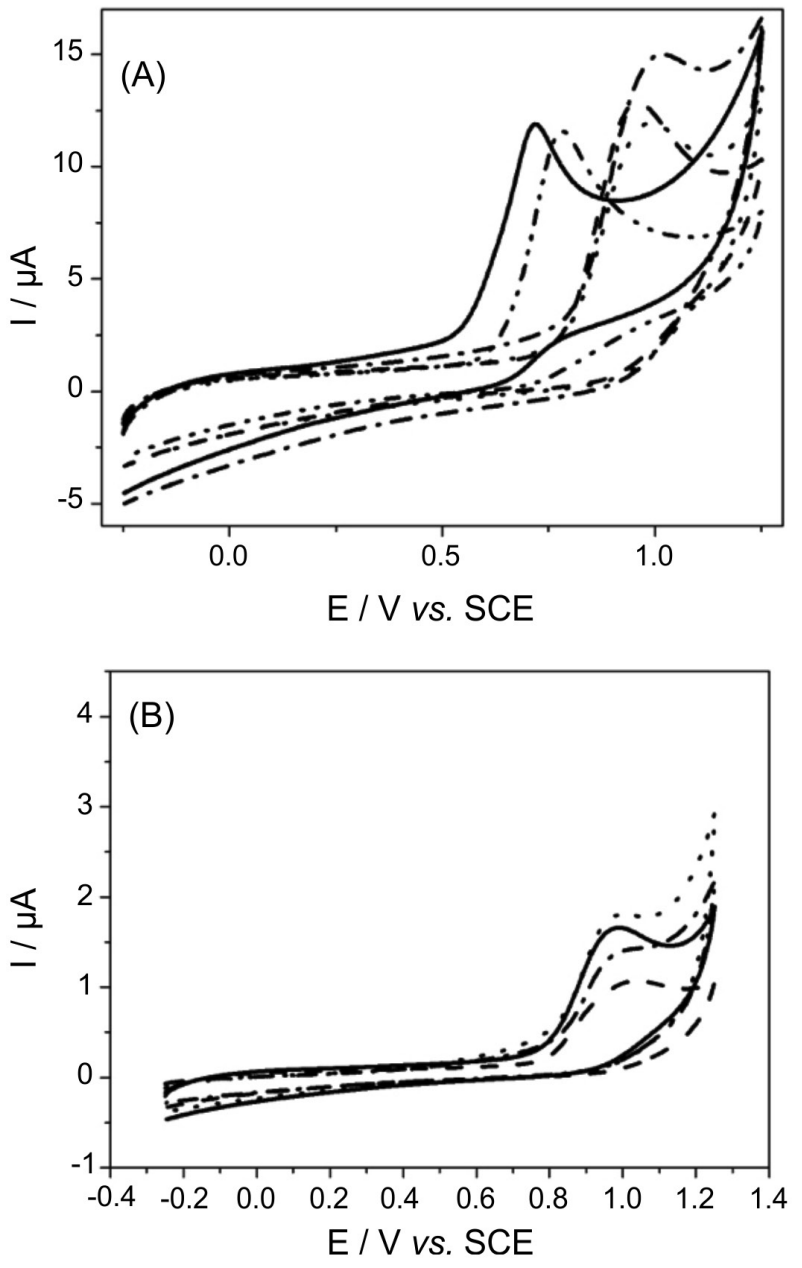

Figure 9. Cyclic voltammograms obtained at glassy carbon electrode containing $0.25 \mathrm{mmol} \mathrm{L}^{-1}$ of MP in supporting electrolyte different $0.1 \mathrm{~mol} \mathrm{~L}^{-1}$ (pH 7.0). (A) Anion: $\mathrm{PO}_{4}^{3-}(-), \mathrm{CH}_{3} \mathrm{COO}^{-}(-. .-), \mathrm{NO}_{3}^{-}(-.-$.$) ,$ $\mathrm{SO}_{4}{ }^{2-}(---), \mathrm{Cl}^{-}(\ldots)$. (B) Cation: $\mathrm{K}^{+}(\ldots), \mathrm{Na}^{+}(-), \mathrm{Li}^{+},(-\cdot-\cdot), \mathrm{NH}_{4}^{+}(---)$, $\mathrm{Cl}-$ salts. $\mathrm{E}_{\text {initial }}=-0.25 \mathrm{~V} ; \mathrm{E}_{1}=1.25 \mathrm{~V} ; \mathrm{E}_{\text {final }}=-0.25 \mathrm{~V}$ and $\mathrm{n}=100 \mathrm{mVs}^{-1}$.

in good agreement with the calculated values for the electronic descriptors. The energies calculated for the formation of the radical forms of parabens indicate that the $\mathrm{BzP}$ and BP are oxidized more easily than PP, EP and MP, showing that the electron donating character of the alkyl side chain contributes slightly to the oxidation process and is not negligible. Therefore the oxidation of parabens and other phenolic analogues to the quinonic forms showed great dependence on the substituent pattern. The results also showed high stability (high anodic potentials) and irreversible behavior, which limits the application of these compounds as antioxidants.

\section{Acknowledgments}

The authors would like to thank Fundação de Amparo à Pesquisa do Estado de Goiás (FAPEG), Fundação de Amparo à Pesquisa do Estado de São Paulo (FAPESP) 
and Conselho Nacional de Desenvolvimento Científico e Tecnológico (CNPq).

\section{References}

1. Blanco, E.; Casais, M. D. C.; Mejuto, M. D. C.; Cela, R.; Anal. Chim. Acta 2009, 647, 104.

2. Al-Shamma, A.; Drake, S.; Flynn, D. L.; Mitscher, L. A.; Park, Y. H.; Rao, G. S. R.; Simpson, A.; Swayze, J. K.; Veysoglu, T.; Wu, D. S.; J. Nat. Prod. 1981, 44, 745.

3. Nicoli, S.; Zani, F.; Bilzi, S.; Bettini, R.; Santi, P.; Eur. J. Pharm. Biopharm. 2008, 69, 613.

4. Eriksson, E.; Andersen, H. R.; Ledin, A.; J. Hazard. Mater. 2008, 156, 240.

5. Soni, M. G.; Taylor, S. L.; Greenberg, N. A.; Burdock, G. A.; Food Chem. Toxicol. 2002, 40, 1335.

6. Lemini, C.; Jaimez, R.; Avila, M. E.; Franco, Y.; Larrea, F.; Lemus, A. E.; Toxicol. Ind. Health. 2003, 19, 69.

7. Byford, J. R.; Shaw, L. E.; Drew, M. G.; Pope, G. S.; Sauer, M. J.; Darbre, P. D.; J. Steroid Biochem. Mol. Biol. 2002, 80, 49.

8. Elder, R. L.; J. Am. Coll. Toxicol. 1984, 3, 147.

9. Korotkova, E. I.; Avramchik, O.A.; Angelov, T. M.; Karbainov, Y. A.; Electrochim. Acta 2005, 51, 324.

10. Xiuping, Z.; Shaoyuan, S.; Junjun, W.; Fanxiu, L. V.; Huazhang, Z.; Jiangtao, K.; Qi, H.; Jinren, N.; Environ. Sci. Technol. 2007, 41,6541 .

11. Lien, E. J.; Ren; S.; Bui, H. H.; Wang, R.; Free Radical Biol. Med. 1999, 26, 285.

12. Regueiro, J.; Becerril, E.; Jares, C.G.; Llompart, M.; J. Chromatogr., A 2009, 23, 4693.

13. Kang, H. S.; Kim, H.; J. Pharm. Biomed. Anal. 1997, 15, 1359.

14. Radovan, C.; Cinghita, D.; Manea, F.; Mincea, M.; Cofan, C.; Ostafe, V.; Sensors 2008, 8, 4330.

15. Gunckel, S.; Santander, P.; Cordano, G.; Ferreira, J.; Munoz, S.; Nunez-Vergara, L. J.; Squella, J. A.; Chem. Biol. Interact. 1998, 114, 45.

16. Leopoldini, M.; Marino, T.; Russo, N.; Toscano, M.; J. Phys. Chem. A 2004, 108, 4916.

17. Wright, J. S.; Johnson, E. R.; DiLabio, G. A.; J. Am. Chem. Soc. 2001, 123, 1173.
18. Mandado, M.; Grana, A.; Mosquera, R.; Chem. Phys. Lett. 2004, $400,169$.

19. Neese, F.; ORCA An ab Initio, Density Functional, and Semiempirical Program Package, Version 2.8, University of Bonn: Germany, 2010.

20. Neese, F.; WIREs: Comput. Mol. Sci. 2012, $2,73$.

21. Kossmann, S.; Neese, F.; J. Chem. Theory Comput. 2010, 6, 2325.

22. Schäfer, A.; Huber, C.; Ahlrichs, R.; J. Chem. Phys. 1994, 100, 5829.

23. Neese, F.; Wennmohs, F.; Hansen, A.; Becker, U.; Chem. Phys. 2009, 356, 98

24. Ahlrichs, R.; Furche, F.; Hättig, C.; Klopper, W. M.; Sierka, M.; Weigend, F.; TurboMole Basis Set Library; TURBOMOLE GmbH: Karlsruhe, Germany, 2011; ftp.chemie.uni-karlsruhe. de/pub/ BASES accessed in September, 2011.

25. Kossmann, S.; Neese, F.; J. Phys. Chem. A 2010, 114, 11768.

26. Weigend, F.; Ahlrichs, R.; Phys. Chem. Chem. Phys. 2005, 7 , 3297.

27. Shen, L. Zhang, H. Y.; Ji, H. F.; Theochem. 2008, 856, 119.

28. North, M.; Bhattacharyya, S.; Truhlar, D. G.; J. Phys. Chem. B 2010, 114, 14907.

29. Neese, F.; Schwabe, T.; Kossmann, S.; Schirmer, B.; Grimme, S.; J. Chem. Theory Comput. 2009, 5, 3060.

30. Kurlancheek, W.; Head-Gordon, M.; Mol. Phys. 2009, 107, 1223.

31. Osorio, G.; Frontana, C.; Guadarrama, P.; Frontana-Uribe, B.; J. Phys. Org. Chem. 2004, 17, 439.

32. Vessecchi, R.; Naal, Z.; Lopes, J. N. C.; Galembeck, S. E.; Lopes, N. P.; J. Phys. Chem. A 2011, 115, 5453.

33. Politzer, P.; Abu-awwad, F.; Theor. Chem. Acc. 1998, 83.

34. Martins, I.; Carreira, F. C.; Canaes, L. S.; Campos-Junior, F. A. S.; Cruz, L. M. S.; Rath, S.; Talanta 2011, 85, 1.

Submitted: December 10, 2010

Published online: January 31, 2012

FAPESP has sponsored the publication of this article. 